\title{
Enrique Fanta Nuñez, nuevo miembro honorario de la Sociedad Chilena de Infectología*
}

\author{
Enrique Fanta Nuñez, new honorary member of the Chilean Infectious \\ Disease Society
}

La Presidenta de nuestra Sociedad, María Elena Santolaya me ha conferido el honor, tremendo honor, emocionado honor, de presentar al Dr. Enrique Fanta para la nominación de Miembro Honorario de nuestra Sociedad Chilena de Infectología.

Hablar de Enrique Fanta es hablar de la historia de la Pediatría chilena y de Latinoamérica, esa historia que ha dejado huella, más allá de nuestra cordillera y nuestro mar, hacia la América morena de Centroamérica, la América indígena de la región del Chaco, la América gaucha de nuestros hermanos trasandinos. Es que Enrique Fanta, integrante de esa hermandad ya mítica, a estas alturas legendaria con los Drs. Julio Meneghello, Humberto Soriano, Juan Macaya, Mafalda Rizardini, y muchos otros, en el también mítico Hospital Roberto Del Río, tuvieron una marcada y reconocida influencia en el desarrollo de la Pediatría del continente, huella que persiste hasta el día de hoy y que los algo más jóvenes, mucho a quienes tuvo desnudos y desnudas entre sus brazos, (como pediatra por cierto) reconocemos en cada uno de nuestros viajes, al constatar los vividos testimonios de sus discípulos esparcidos en los confines de nuestro querido continente.

Enrique Fanta ha sido una persona de maravillosos contrastes, que ha tenido una profunda influencia en las generaciones de pediatras e infectólogos de nuestro país. En su época de formador que por cierto no ha terminado, primero en la Universidad de Chile y luego en la Pontificia Universidad Católica, sus discípulos dentro de los cuales me incluyo con orgullo, lo recordamos como un profesor exigente, crítico, actualizado, a veces implacable; una persona que se cubría con piel de lobo para exigir rigurosidad y consistencia, pero que en el fondo tenía un corazón blando y sensible, que se regocijaba y regocija ante las personas creativas, honestas, y perseverantes.
Es conocido que Enrique Fanta en sus implacables interrogatorios clínicos de ayer hizo sufrir e incluso llorar a muchos becados y becadas de Pediatría de entonces; pero no es menos cierto que su aparente severidad influyó en el desarrollo de la excelencia de sus estudiantes de todo el continente, cualidades que hoy lo aprecian en su etapa de madurez, sus discípulos de ayer, profesores y formadores de hoy.

Enrique Fanta es un eterno buscador de la verdad, y por eso, Enrique es hoy tan joven como hace treinta o cuarenta años; quienes lo escuchamos opinar ayer en una sesión científica, o quienes compartimos con él en una carrera o partido de voleyball solidario (destacamos que antaño fue seleccionado de voleyball) reconocimos a un maestro que ha aprendido la humildad y sabiduría que da la vida después de muchos años vividos. Un hombre que ha sabido adaptarse a la vorágine de los avances de la ciencia, que se enorgullece del éxito de sus discípulos, y que además lo siente y expresa con alegría manifiesta, con su alma eterna de niño, eso es un verdadero maestro, un ejemplo de vida, Eso es Enrique Fanta hoy.

Enrique es además uno de los creadores de la especialidad de Infectología Pediátrica en el continente, siendo socio fundador de la Sociedad Latinoamericana de Infectología Pediátrica; es un colaborador constante, abnegado y disciplinado de la Sociedad Chilena de Infectología.

Hablar de Enrique Fanta sin hablar de Dorita, su esposa y compañera de toda la vida, sería un incordio, una irrealidad. Dorita es una de esas bellezas de persona, que se dan de tarde en vez, que han dado todo para apoyar a su pareja, pero sin dejar de ser ella en si misma una persona extraordinaria en su propio desarrollo. Enrique sin Dorita, no sería Enrique; quiénes pueden decir esto luego de tantos años vividos.. 


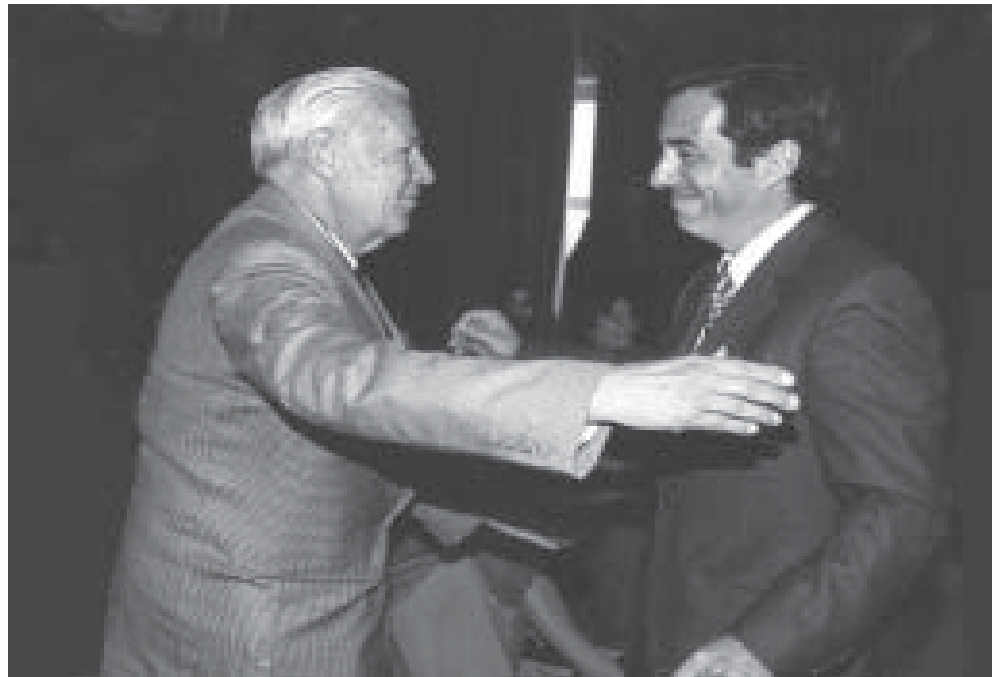

En la fotografía, Enrique Fanta N recibe el diploma que certifica su designación como miembro honorario de la Sociedad Chilena de Infectología, de manos de su discípulo Miguel O’Ryan G.

Y además, como si lo anterior no fuera suficiente, Enrique Fanta ha sido un médico altruista quien ha extendido su trabajo hacia las comunidades de niños en Guaylandia; demostrando una vez más su desprendimiento como médico y ser humano.

Es por esto y muchos otros motivos que estoy cierto muchos de sus discípulos estarían dispuestos a atestiguar, que me enorgullezco en presentar al Dr. Enrique Fanta a la nominación de Miembro Honorario de la Sociedad Chilena de Infectología.

Miguel O'Ryan G. Programa de Microbiología, Instituto de Ciencias Biomédicas, Facultad de Medicina, Universidad de Chile 